\title{
Screening for Mitochondrial tRNA Mutations in 318 Patients with Dilated Cardiomyopathy
}

\author{
Yujuan Qi Zhenhua Wu Yaobang Bai Yan Jiao Peijun Li \\ Intensive Care Unit, Tianjin Chest Hospital, Tianjin, China
}

\section{Keywords}

Dilated cardiomyopathy - Mitochondrial tRNA - Mutations ·

Mitochondrial dysfunction

\begin{abstract}
Objectives: Dilated cardiomyopathy (DCM) is a complex cardiovascular disease with unknown etiology. Although nuclear genes play active roles in DCM, mitochondrial dysfunction was believed to be involved in the pathogenesis of DCM. The objective of this study was to analyze the association between mitochondrial tRNA (mt-tRNA) mutations and DCM. Materials and Methods: We performed a mutational analysis of mt-tRNA genes in a cohort of 318 patients with DCM and 200 age- and gender-matched control subjects. To further assess their pathogenicity, phylogenetic analysis and mitochondrial functions including mtDNA copy number, ATP, and ROS were analyzed. Results: Seven possible pathogenic mutations, i.e., MT-TL1 3302A $>$ G, MT-TI 4295A>G, MTTM 4435A>G, MT-TA 5655T>C, MT-TH 12201T>C, MT-TE $14692 A>G$, and $M T-T T 15927 \mathrm{G}>A$, were identified in the DCM group but were absent in controls. These mutations occurred at extremely conserved nucleotides of corresponding tRNAs and led to the failure in tRNAs metabolism. Moreover, a significant reduction in ATP and mtDNA copy number and a marked increase in ROS level were observed in polymononuclear leukocytes (PMNs) derived from the DCM patients carrying these mt-tRNA mutations, suggesting that these
\end{abstract}

mutations may cause mitochondrial dysfunction that was responsible for DCM. Conclusions: Our data indicated that mttRNA mutations may be the molecular basis for DCM, which provides novel insights into the pathophysiology of DCM that manifested as mitochondrial dysfunction.

\section{(c) 2022 The Author(s).}

Published by S. Karger AG, Basel

\section{Introduction}

Dilated cardiomyopathy (DCM) is a nonischemic heart muscle disease with structural and functional myocardial abnormalities characterized by dilation of the ventricular chamber and impaired contraction [1]. Patients with DCM typically exhibit ventricular enlargement and subsequent cardiac dysfunction, which can be accompanied by arrhythmia, thromboembolism, or sudden death $[2,3]$. The incidence of DCM is reported to be 5-7 cases of 100,000 people annually [4]. However, to date, the molecular mechanisms that trigger the development of DCM remain poorly understood.

Cardiac tissue requires a persistent production of energy in order to exert its pumping function $[5,6]$. Therefore, maintenance of this function relies on mitochondria that represent the "powerhouse" of all cardiac activities [7]. In these cells, mitochondria occupy 30\% of the total

Yujuan Qi and Zhenhua Wu have contributed equally to this work.
Karger@karger.com www.karger.com/hhe

Karger $\stackrel{\text { ' }}{5}$

GOPEN ACCESS
(C) 2022 The Author(s)

Published by S. Karger AG, Basel

This is an Open Access article licensed under the Creative Commons Attribution-NonCommercial-4.0 International License (CC BY-NC) (http://www.karger.com/Services/OpenAccessLicense), applicable to the online version of the article only. Usage and distribution for commercial purposes requires written permission.
Correspondence to:

Peijun Li, lipeijun0001@yeah.net 
volume of the cell and supply, through oxidative phosphorylation (OXPHOS), approximately $6 \mathrm{~kg}$ of ATP per day that is required to sustain cardiac function [8]. Indeed, human mitochondrial DNA (mtDNA) encodes 13 subunits of the respiratory chain complexes, 22 tRNAs, and 2 rRNAs; the replication, transcription, translation, and repair of mtDNA are controlled by proteins encoded by nuclear DNA (nDNA) [9]. Due to the lack of histone protection and a poor DNA repair system, $\mathrm{mtDNA}$ has a much higher mutation rate than nDNA [10]. Most recently, several mtDNA mutations have been reported to be associated with DCM, such as 3243A $>\mathrm{G}$ and 3303C $>\mathrm{T}$ mutations in MT-TL1 [11, 12], 15024G $>A$ and $15482 \mathrm{~T}>\mathrm{C}$ mutations in MT-CYB gene [13], and $12338 \mathrm{~T}>\mathrm{C}$ mutation in MT-ND5 gene [14]. However, these studies reported only on relatively small-sized samples of pedigrees, while the spectrum and association of mutations in $22 \mathrm{mt}$-tRNA with DCM in large populations remain to be explored.

With this aim, in the current study, we first performed a mutational analysis of $22 \mathrm{mt}$-tRNA genes in a cohort of 318 subjects with DCM and 200 controls. These mutations were further assessed by phylogenetic evaluations as well as structural and mitochondrial functional analysis. As a result, we identified 7 possibly pathogenic mutations in mt-tRNA genes.

\section{Materials and Methods}

\section{Study Population}

The study population was composed of 318 patients (200 males and 118 females, aged $59 \pm 15$ years) with a clinical diagnosis of DCM, who were recruited from Tianjin Chest Hospital. All participants had Han ethnicity. The diagnosis of DCM was performed in the presence of left ventricular ejection fraction $<50 \%$ at the time of diagnosis in the absence of any known possible cause of left ventricular dysfunction $[15,16]$. Moreover, 200 healthy subjects $(110$ males and 90 females, aged $49 \pm 13$ years) were recruited from the Healthy Examination Center of our hospital. The inclusion criteria were as follows: healthy subjects without any diseases, no history of cardiovascular disease, no drug use, normal diet, and alcohol consumption $<30 \mathrm{~g} /$ day. Exclusion criteria included a family history of mitochondrial disease, such as hearing loss, vision loss, neurological disease, or cancer; individuals who were taking regular medication were also excluded. All participants signed the informed consent prior to inclusion. The study was approved by the ethics committee of Tianjin Chest Hospital and conducted in accordance with the Declaration of Helsinki and the International Conference on Harmonization Guidelines for Good Clinical Practice (approval number: 2020YS-030-01).

Mutational Analysis of $m t-t R N A s$

Blood samples from each subject were collected in the morning between 7:00 a.m. and 10:00 a.m. after an overnight fast. The ge- nomic DNA was isolated from peripheral blood of all the subjects using Paxgene Blood DNA Isolation Kits (QIAGEN). The fragments spanning entire tRNA genes of 318 Han Chinese patients with DCM and 200 controls were PCR amplified by use of sets of the light-strand and the heavy-strand oligonucleotide primers, as described elsewhere [17] (Table 1). In individuals found to have potentially pathogenic mutations in tRNA genes, fragments that spanned the remainder of the mitochondrial genome were also amplified via PCR and were used to establish the mtDNA haplogroups of these individuals. The PCR reagents (all obtained from Takara Bio, Inc.) were as follows: $200 \mu \mathrm{M}$ dNTPs, $2 \mu \mathrm{L} 10 \times$ PCR buffer $\left(10 \times 0.2 \mu \mathrm{L}\right.$ Taq DNA polymerase, and $15 \mathrm{mmol} / \mathrm{L} \mathrm{Mg}^{2+}$. PCR was performed under the following thermocycling conditions: $95^{\circ} \mathrm{C}$ for $5 \mathrm{~min}, 94^{\circ} \mathrm{C}$ for $10 \mathrm{~s}, 60^{\circ} \mathrm{C}$ for $30 \mathrm{~s}, 30$ cycles at $72^{\circ} \mathrm{C}$ for $60 \mathrm{~s}$, and $72^{\circ} \mathrm{C}$ for $10 \mathrm{~min}$ for extension. Bidirectional sequencing in both directions was conducted in order to confirm amplicon sequences, after which sequences were compared with the revised Cambridge Reference sequence (rCRS, GenBank accession number: NC_012920.1) [18].

\section{Phylogenetic Analysis}

A total of 17 vertebrates mtDNA sequences were used in the interspecific analysis. These species were as follows: Bos taurus, Cebus albifrons, Colobus guereza, Gorilla gorilla, Homo sapiens, Hylobates lar, Lemur catta, Macaca mulatta, Macaca sylvanus, Mus musculus, Nycticebus coucang, Pan paniscus, Pan troglodytes, Pongo pygmaeus, Pongo pygmaeus abelii, Tarsius bancanus, and Papio hamadryas. The conservation index (CI) was calculated by comparing the human mtDNA mutations with other 16 vertebrates. A CI $\geq 75 \%$ was regarded to have functional importance [19].

\section{Haplogroup Classification}

The entire mtDNA sequences of 9 subjects with putative pathogenic mt-tRNA mutations were assigned to the Asian mitochondrial haplogroups based on the PhyloTree database (http://www. phylotree.org) [20].

\section{mtDNA Copy Number Analysis}

The mtDNA copy number was assessed by real-time quantitative PCR using an Applied Biosystems 7900 Sequence Detection System (Applied Biosystems, Foster City, CA, USA) according to a previous report [21]. The following primers were used for realtime PCR analysis: for $\beta$-globin gene, forward: $5^{\prime}$-CTATGGGACGCTTGATGT-3', reverse: 5'-GCAATCATTCGTCTGTTT-3'; for mtDNA (mt-ND1 gene), forward: $5^{\prime}$-CACCAGCCTAACCAGATTTC-3', reverse: 5'-GGGTTGTATTGATGAGATTAGT-3'.

\section{Isolation of Human Polymononuclear Leukocytes}

The human polymononuclear leukocytes (PMNs) of the 9 subjects with putative pathogenic mt-tRNA mutations, as well as those of 9 healthy subjects, were isolated according to the protocol described previously [22]. Cells were grown in Hank's buffer salt solution before further analysis.

\section{Analysis of ATP Production}

The levels of ATP production from 9 subjects with putative pathogenic mt-tRNA mutations, together with those from 9 healthy subjects, were measured using the protocols described elsewhere [23]. 
Table 1. Primer sequences for amplification of $22 \mathrm{mt}$-tRNAs

\begin{tabular}{|c|c|c|c|c|}
\hline Target gene & Primer name & Primer Sequence $\left(5^{\prime}-3^{\prime}\right)$ & $\mathrm{Tm},{ }^{\circ} \mathrm{C}$ & Product size \\
\hline MT-TF & $\begin{array}{l}\text { MT-1F } \\
\text { MT-1R }\end{array}$ & $\begin{array}{l}\text { CTCCTCAAAGCAATACACTG } \\
\text { TGCTAAATCCACCTTCGACC }\end{array}$ & 61 & 802 bp \\
\hline MT-TV & $\begin{array}{l}\text { MT-2F } \\
\text { MT-2R }\end{array}$ & $\begin{array}{l}\text { CGATCAACCTCACCACCTCT } \\
\text { TGGACAACCAGCTATCACCA }\end{array}$ & 58 & 802 bp \\
\hline MT-TL1 & $\begin{array}{l}\text { MT-4F } \\
\text { MT-4R }\end{array}$ & $\begin{array}{l}\text { AAATCTTACCCCGCCTGTT } \\
\text { AGGAATGCCATTGCGATTAG }\end{array}$ & 60 & 887 bp \\
\hline $\begin{array}{l}\text { MT-TI } \\
\text { MT-TQ } \\
\text { MT-TM }\end{array}$ & $\begin{array}{l}\text { MT-6F } \\
\text { MT-6R }\end{array}$ & $\begin{array}{l}\text { TGG CTC CTT TAA CCT CTC CA } \\
\text { AAG GAT TAT GGA TGC GGT TG }\end{array}$ & 60 & $898 \mathrm{bp}$ \\
\hline $\begin{array}{l}\text { MT-TA } \\
\text { MT-TN } \\
\text { MT-TC }\end{array}$ & $\begin{array}{l}\text { MT-8F } \\
\text { MT-8R }\end{array}$ & $\begin{array}{l}\text { CTAACCGGCTITTGCCC } \\
\text { ACCTAGAAGGTTGCCTGGCT }\end{array}$ & 60 & $814 b p$ \\
\hline $\begin{array}{l}\text { MT-TS1 } \\
\text { MT-TD }\end{array}$ & $\begin{array}{l}\text { MT-11F } \\
\text { MT-11R }\end{array}$ & $\begin{array}{l}\text { ACGCCAAAATCCATTTCACT } \\
\text { CGGGAATTGCATCTGTTITI }\end{array}$ & 58 & $987 \mathrm{bp}$ \\
\hline MT-TK & $\begin{array}{l}\text { MT-12F } \\
M T-12 R\end{array}$ & $\begin{array}{l}\text { ACG AGT ACA CCG ACT ACG GC } \\
\text { TGG GTG GTT GGT GTA AAT GA }\end{array}$ & 60 & $900 \mathrm{bp}$ \\
\hline $\begin{array}{l}\text { MT-TG } \\
\text { MT-TR }\end{array}$ & $\begin{array}{l}\text { MT-15F } \\
\text { MT-15R }\end{array}$ & $\begin{array}{l}\text { TCTCCATCTATTGATGAGGGTCT } \\
\text { AATTAGGCTGTGGGTGGTTG }\end{array}$ & 60 & $891 \mathrm{bp}$ \\
\hline $\begin{array}{l}\text { MT-TH } \\
\text { MT-TS2 } \\
\text { MT-TL2 }\end{array}$ & $\begin{array}{l}\text { MT-18F } \\
\text { MT-18R }\end{array}$ & $\begin{array}{l}\text { TATCACTCTCCTACTTACAG } \\
\text { AGAAGGTTATAATTCCTACG }\end{array}$ & 55 & $866 \mathrm{bp}$ \\
\hline MT-TE & $\begin{array}{l}\text { MT-21F } \\
\text { MT-21R }\end{array}$ & $\begin{array}{l}\text { GCATAATTAAACTTTACTTC } \\
\text { AGAATATTGAGGCGCCATTG }\end{array}$ & 55 & 938 bp \\
\hline $\begin{array}{l}\text { MT-TT } \\
\text { MT-TP }\end{array}$ & $\begin{array}{l}\text { MT-22F } \\
\text { MT-22R }\end{array}$ & $\begin{array}{l}\text { TGAAACTTCGGCTCACTCCT } \\
\text { GAGTGGTTAATAGGGTGATAG }\end{array}$ & 60 & $1,162 \mathrm{bp}$ \\
\hline
\end{tabular}

Tm, annealing temperature.

ROS Analysis

The ROS level was analyzed by fluorometry. $2 \times 10^{6}$ cells were first incubated with the fluorescent probe $2^{\prime}, 7^{\prime}$-dichlorodihydrofluorescein (DCFH) for about $30 \mathrm{~min}$, then the cells were analyzed by fluorescence plate reader, as described elsewhere [24].

\section{Statistical Analysis}

Student's $t$ test was used to assess the statistical significance between unpaired samples. All analyses were performed using the SPSS software version 22.0. We regarded a $p<0.05$ as statistically significant.

\section{Results}

\section{Clinical Presentation}

From January 2018 to January 2020, a total of 318 patients with a clinical diagnosis of DCM from Tianjin
Chest Hospital participated in this study. The ratio of males to females was 1.69:1. The age of these patients ranged from 42 to 78 years, with a median age of 55 years. The age at onset of DCM was 40-75 years, with an average of 59 years. In the DCM group, left ventricular ejection fraction was $31.55 \pm 9.55 \%$ and left ventricular end diastole diameter was $6.76 \pm 0.83 \mathrm{~mm}$. Furthermore, 200 healthy Han Chinese subjects who did not have a family history of mitochondrial diseases were obtained from the same region. The age of these participants ranged from 35 to 55 years, with a median age of 42 years.

\section{Mutational Screening for DCM-Associated mt-tRNA Mutations}

We sequenced the complete mt-tRNA genes in a cohort of 318 affected subjects with DCM and 200 healthy controls. By comparing with the rCRS [18], 7 potentially 


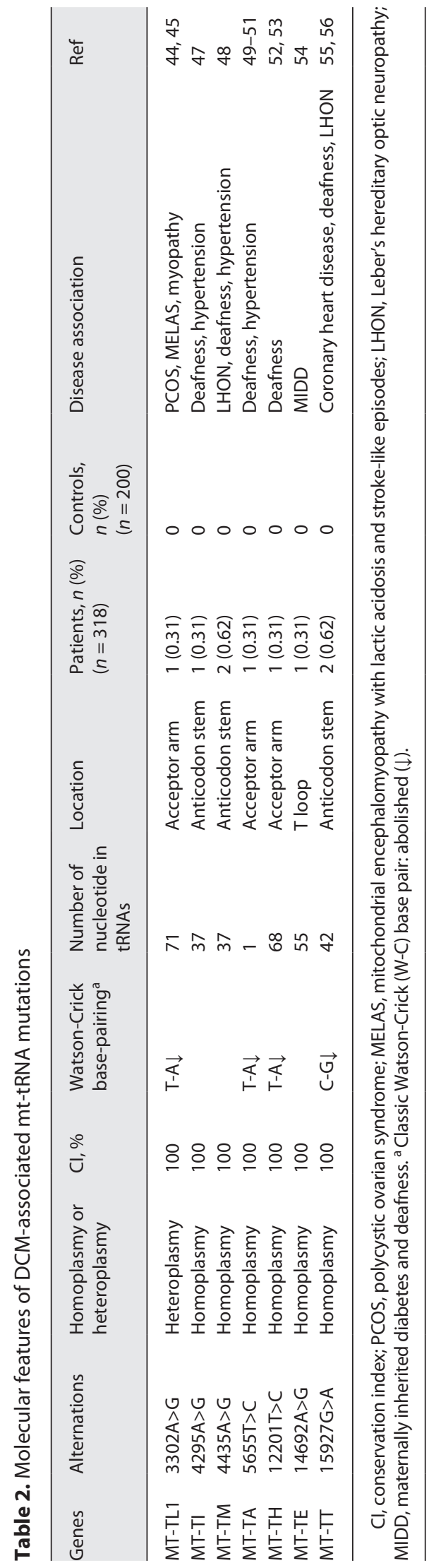

pathogenic mutationswere identified:MT-TL13302A $>\mathrm{G}$, MT-TI 4295A $>$ G, MT-TM 4435A $>$ G, MT-TA 5655T $>$ C, MT-TH 12201T $>$ C, MT-TE14692A $>$ G, and MT-TT $15927 \mathrm{G}>\mathrm{A}$. Particularly, 2 patients carried the $4435 \mathrm{~A}>\mathrm{G}$ mutations, 2 patients harbored the $15927 \mathrm{G}>\mathrm{A}$ mutations, while other pathogenic mutations, including 3302A $>\mathrm{G}$, $4295 \mathrm{~A}>\mathrm{G}, 5655 \mathrm{~T}>\mathrm{C}, 12201 \mathrm{~T}>\mathrm{C}$, and $14692 \mathrm{~A}>\mathrm{G}$, were detected in 1 subject each (Table 2).

\section{Assessment of the Pathogenicity}

To further assess the pathogenicity of mt-tRNA mutations, we used the following criteria: first, the mutation itself occurred $<1 \%$ in control subjects; second, the CI was $\geq 75 \%$, as proposed by Ruiz-Pesini and Wallace [25]; third, the mutation may have a functional impact on mt-tRNA genes. For this purpose, we first performed the phylogenetic conservation analysis of these mt-tRNA mutations, as shown in Table 2. We noticed that all these tRNA mutations were well conserved from 17 species. In addition, the locations of these mutations within tRNA secondary structures are shown in Figure 1. Of these, 3 mutations occurred at the acceptor arm, 3 mutations were localized at the anticodon stem, and 1 mutation occurred at T loop. Moreover, 4 mutations (3302A $>$ G, 5655T $>C, 12201 \mathrm{~T}>\mathrm{C}$, and $15927 \mathrm{G}>\mathrm{A}$ ) disrupted the highly conserved basepairings and may have functional significance. In particular, as shown in Figure 2, sequence alignment of MT-TH gene revealed that the $12201 \mathrm{~T}>\mathrm{C}$ mutation was very conserved from different species $(\mathrm{CI}=100 \%)$. Similarly, the CIs of other mutations $(3302 \mathrm{~A}>\mathrm{G}, 5655 \mathrm{~T}>\mathrm{C}, 4435 \mathrm{~A}>\mathrm{G}$, $14692 \mathrm{~A}>\mathrm{G}$, and $15927 \mathrm{G}>\mathrm{A}$ ) were also evolutionary conserved. All these mutations were identified in the DCM group only, but were absent in 200 controls.

Clinical Features of 9 Probands Carrying 1 of Putative Pathogenic mt-tRNA Mutations

As shown in Table 3, 9 patients (4 males and 5 females) with DCM carried the pathogenic/likely pathogenic tRNA mutations, accounting for $2.8 \%$ of the cases in our cohort. The age at onset of DCM in these subjects ranged from 44 to 68 years, with a mean age of 57 years. Moreover, a comprehensive medical history showed that 4 probands had a family history of cardiovascular diseases, such as hypertension, coronary heart disease, and heart failure.

Analysis of the Complete mtDNA Genomes in 9 DCM Individuals Carrying 1 of the Pathogenic/Likely Pathogenic mt-tRNA Mutations

We further sequenced the whole mitochondrial genomes of $9 \mathrm{DCM}$ patients harboring 1 of the potentially 


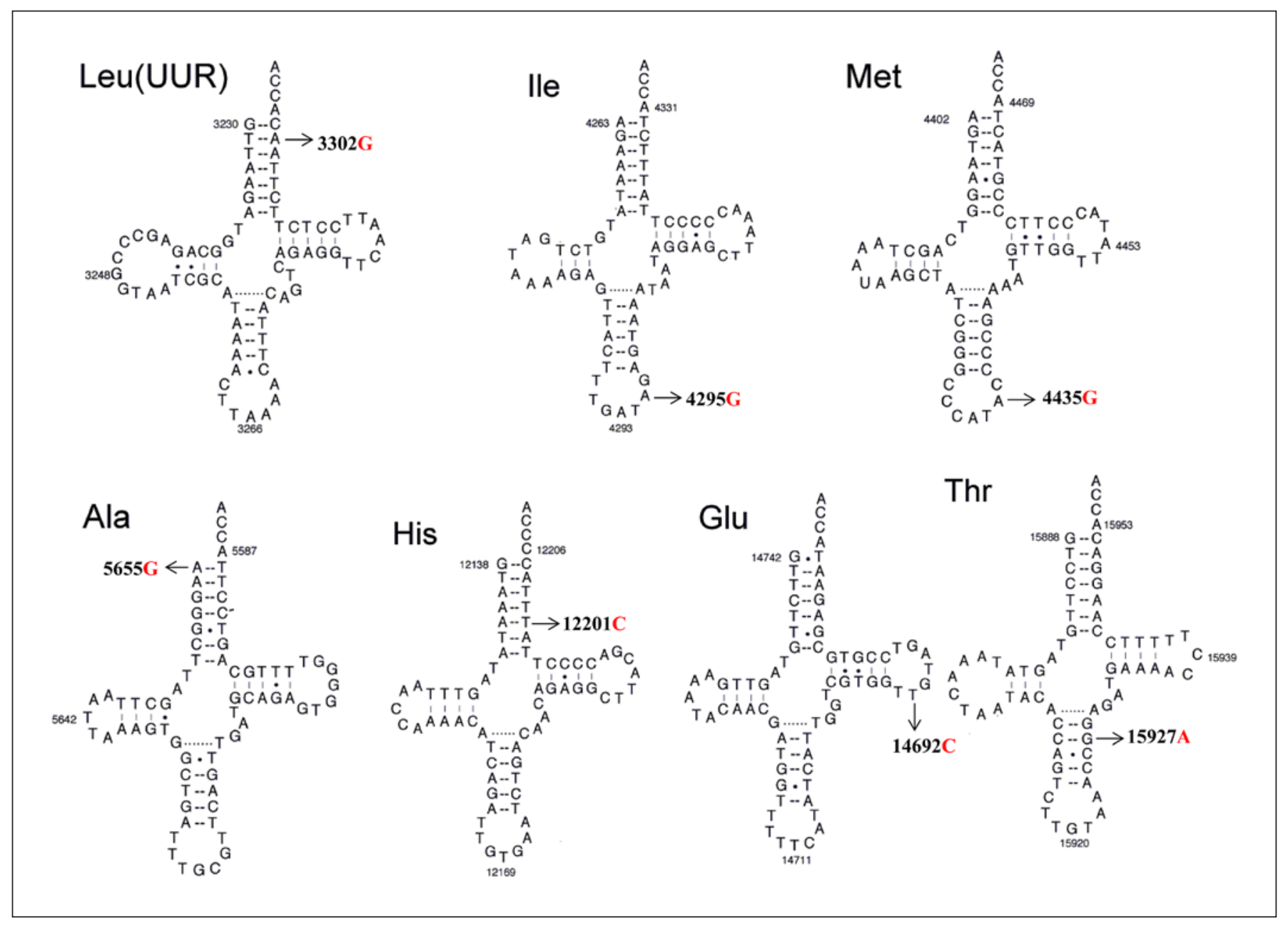

Fig. 1. Cloverleaf structures of MT-TL1, MT-TI, MT-TM, MT-TA, MT-TH, MT-TE, and MT-TT. Arrows indicate the positions of DCM-associated mtDNA mutations.

pathogenic mt-tRNA mutations to examine if there were any other functional mtDNA mutations. As shown in Table 3, $6 \mathrm{mtDNA}$ functional mutations were identified by Sanger sequencing. Of them, the MT-ND1 3398T $>\mathrm{C} \mathrm{mu-}$ tation co-existed with the MT-TI 4295A $>\mathrm{G}$ mutation, the known CO1/MT-TS1 7444G>A co-existed with the MTTM 4435A $>$ G mutation, MT-ND6 14502T $>C$ co-existed with MT-TA 5655T $>$ C, and the MT-TH $12201 \mathrm{~T}>\mathrm{C} \mathrm{mu-}$ tation was found in 1 patient carrying the MT-ND2 $5178 \mathrm{C}>\mathrm{A}$ mutation, MT-TE $14692 \mathrm{~A}>\mathrm{G}$ was identified in a patient with the MT-ND5 $12811 \mathrm{~T}>\mathrm{C}$ mutation, and the MT-TT $15927 \mathrm{G}>$ A mutation occurred in a patient carrying the MT-RNR1 1095T $>C$ mutation. Interestingly, the $3398 \mathrm{~T}>\mathrm{C}$ mutation has been found to contribute to mitochondrial disorders, such as mitochondriopathy [26], left ventricular noncompaction [27], and hearing loss
[28]. By molecular level, the $3398 \mathrm{~T}>\mathrm{C}$ mutation resulted in the substitution of a highly conserved methionine for a threonine at amino acid position 31 of the MT-ND1 gene. Biochemical analysis revealed that this mutation caused a reduction of complex I activity and impaired the OXPHOS function in defective mitochondrial respiratory chain complex hepatocytes [29]. Moreover, the $7444 \mathrm{G}>\mathrm{A}$ mutation resulted in a read-through of the stop codon AGA of the MT-CO1 message, thereby adding 3 amino acids (Lys-Gln-Lys) to the C-terminal of the polypeptide. Thus, the mutated polypeptide may retain a partial function. Alternatively, the $7444 \mathrm{G}>\mathrm{A}$ mutation was adjacent to the site of the 3 '-end endonucleolytic processing of the L-strand RNA precursor, spanning MT-TS1 and ND6 mRNA [30]. A previous study suggested that the $7444 \mathrm{G}>\mathrm{A}$ mutation may modulate the clinical expression 


\begin{tabular}{|c|c|c|c|c|c|c|c|c|c|c|c|c|c|c|}
\hline \multirow[t]{2}{*}{ Organism } & Acc-stem & D-stem & D-loop & \multicolumn{2}{|l|}{ D-stem } & \multirow{2}{*}{$\begin{array}{l}\text { Ac- } \\
\text { stem } \\
27\end{array}$} & \multirow{2}{*}{$\begin{array}{l}\text { Anticd- } \\
\text { loop } \\
32\end{array}$} & \multirow{2}{*}{$\begin{array}{l}\text { Ac-stem } \\
39\end{array}$} & \multirow[t]{2}{*}{$\begin{array}{c}\text { V- } \\
\text { region }\end{array}$} & \multirow{2}{*}{$\begin{array}{l}\text { T-stem } \\
49\end{array}$} & \multirow{2}{*}{$5^{\text {T-loop }}$} & \multirow{2}{*}{$\begin{array}{l}\text { T-stem } \\
61\end{array}$} & \multicolumn{2}{|l|}{ Ace-stem } \\
\hline & 1 & 910 & 15 & 22 & 26 & & & & & & & & 6668 & 73 \\
\hline Bos taurus & GTAAATA & TA GTTT & AACAA & AAAC & A & TTAGA & TTGTGAA & TCTAA & CAAT & AGAAA & CTCATTAC & CTTCT & TATTTAC & c \\
\hline Cebus albifions & GTAGCTA & TA GTTT & AATTA & AAAC & A & TTAGA & TTGTGAA & TCTAA & TAAT & AGAAG & ACTACAA & CTTCT & TATCTAC & C \\
\hline Colobus guereca & GTAAATA & TA ATTT & AACTA & AAAT & A & CTAGA & TTGTGAA & CCTAG & ACAT & AGAAG & CTTACCG & CTTCT & TATTTAC & C \\
\hline Gorilla gorilla & GTAAATA & TA GTTT & AACCA & AAAC & A & TCAGA & TTGTGAA & TCTGA & TAAC & AGAGG & CTCACAA & CCCCT & TATTTAC & C \\
\hline Homo sapiens & GTAAATA & TA GTTT & AACCA & AAAC & A & TCAGA & TTGTGAA & TCTGA & CAAC & AGAGG & CTTACGA & $\operatorname{cCcCT}$ & TATTTAC & c \\
\hline Hylobates lar & GTAAACA & TA GTTT & AATCA & AAAC & A & TTAGA & TTGTGAA & TCTAA & CAAT & AGAGG & CTCGAAA & CCTCT & TGITTAC & c \\
\hline Lemur catta & GTAAATA & TA GTTT & AAAA & AAAC & A & CTAGA & TTGTGAA & TCCAG & AAAT & AGAAG & CTCAAAC & CTTCT & TATTTAC & C \\
\hline Macaca mulatta & GTAGATA & TA GTTT & AACTA & AAAC & A & TTAGA & TTGTGAA & TCTAA & CCAC & AGAGA & CTTACCA & CCTCT & TATTTAC & c \\
\hline Macaca sylvamus & GTAAATA & TA GTTT & AATTA & AAAC & A & TTAGA & CTGTGAA & TCTAA & CTAT & AGAAG & CTTACCA & CTTCT & TATTTAC & c \\
\hline Mus musculus & GTGAATA & TA GTTT & ACAAA & AAAC & A & TTAGA & CTGTGAA & TCTGA & CAAC & AGGAA & ATAAAC & CTCCT & TATTCAC & c \\
\hline Nycticebus coucang & GTAAATA & TA GTTT & AACAA & AAAC & A & TTAGA & TTGTGAA & TCTAA & CAAT & AGAAG & ACTTAAC & CCTCT & TATTTAC & C \\
\hline Pan paniscus & GTAAATA & TA GTTT & AACCA & AAAC & A & TCAGA & TTGTGAA & TCTGA & CAAC & AGAGG & CTCACGA & $\operatorname{cCCCT}$ & TATTTAC & c \\
\hline Pan troglodytes & GTAAATA & TA GTTT & AACCA & AAAC & A & TCAGA & TTGTGAA & TCTGA & CAAC & AGAGG & CTCACGA & $\operatorname{CCCCT}$ & TATTTAC & c \\
\hline Pongo pygmaeus abelit & GTAAATA & TA GTTT & AACCA & AAAC & A & TCAGA & TTGTGAA & TCTAA & TAAT & $A G G G C$ & CCACAA & $\operatorname{ccccT}$ & TATTTAC & c \\
\hline Tarsius bancamus & GTAAATA & TA GTTT & AAACA & AAAC & $A$ & TTAGA & TTGTGAG & TCTAA & CAAT & AGAAG & CCAAAAA & TTTCT & TATTTAC & c \\
\hline Papio hamadryas & GTAGACA & TA GTTT & AATCA & AAAC & G & TTAGA & CTGTGAA & TCTAA & CTAT & AGAAG & CCCACCA & CTTCT & TGITTAC & C \\
\hline
\end{tabular}

Fig. 2. Alignment of MT-TH gene from different species. The arrow indicates the position 68 , corresponding to the m.12201T $>$ C mutation.

Table 3. mtDNA genetic background and clinical characterization of 9 probands carrying 1 of pathogenic/likely pathogenic DCM-associated mt-tRNA variants

\begin{tabular}{|c|c|c|c|c|c|c|c|c|}
\hline Gene & Mutations & Probands & Sex & $\begin{array}{l}\text { Age at onset, } \\
\text { years }\end{array}$ & $\begin{array}{l}\text { Age at test, } \\
\text { years }\end{array}$ & Family history & $\begin{array}{l}\text { Other functional mtDNA } \\
\text { variants }\end{array}$ & Haplogroup \\
\hline MT-TL1 & $3302 A>G$ & DCM-066 & Male & 67 & 70 & No & None & $\mathrm{F} 2$ \\
\hline MT-TI & $4295 A>G$ & DCM-102 & Female & 55 & 60 & No & MT-ND1 3398T>C & D4 \\
\hline \multirow[t]{2}{*}{ MT-TM } & $4435 A>G$ & DCM-179 & Male & 68 & 72 & $\begin{array}{l}\text { Mother and brother have } \\
\text { hypertension, coronary heart } \\
\text { disease }\end{array}$ & None & G2a \\
\hline & $4435 A>G$ & DCM-128 & Female & 49 & 51 & No & CO1/MT-TS1 7444G>A & D4 \\
\hline MT-TA & $5655 \mathrm{~T}>\mathrm{C}$ & DCM-095 & Male & 59 & 61 & $\begin{array}{l}\text { Mother and sister have } \\
\text { coronary heart disease }\end{array}$ & MT-ND6 14502T>C & $M 22 b$ \\
\hline MT-TH & $12201 \mathrm{~T}>\mathrm{C}$ & DCM-228 & Male & 44 & 47 & No & MT-ND2 5178C>A & $\mathrm{Z3}$ \\
\hline MT-TE & $14692 A>G$ & DCM-300 & Female & 58 & 58 & $\begin{array}{l}\text { Mother has coronary heart } \\
\text { disease }\end{array}$ & MT-ND5 12811T>C & G1a1 \\
\hline \multirow[t]{2}{*}{ MT-TT } & $15927 \mathrm{G}>\mathrm{A}$ & DCM-153 & Female & 53 & 54 & No & MT-RNR1 1095T>C & B5 \\
\hline & $15927 \mathrm{G}>\mathrm{A}$ & DCM-231 & Female & 59 & 62 & Mother died of heart failure & None & B5b2 \\
\hline
\end{tabular}


Fig. 3. Analysis of mitochondrial functions in DCM patients carrying putative pathogenic mt-tRNA mutations and controls. a mtDNA copy number. b ATP qualification. c ROS level.

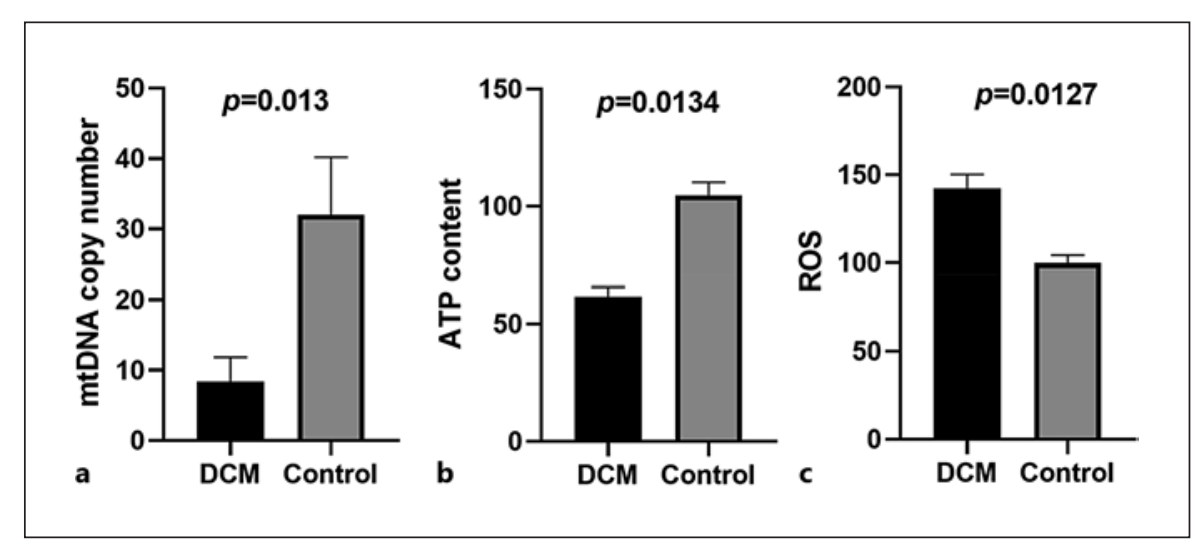

of deafness-associated MT-RNR1 1555A>G mutation [31]. While the homoplasmic $14502 \mathrm{~T}>\mathrm{C}$ mutation caused the substitution of a highly conserved isoleucine for valine at position 58 in MT-ND6 [32], this mutation was regarded to play a synergistic role in increasing the penetrance and expressivity of Leber's hereditary optic neuropathy (LHON)-associated MT-ND4 11778G>A mutation [33]. On the other hand, the MT-ND2 5178C $>$ A mutation has been associated with longevity and type 2 diabetes mellitus [22,34], and the $12811 \mathrm{~T}>\mathrm{C}$ mutation is believed to affect the clinical expression of LHON-related $11778 \mathrm{G}>\mathrm{A}$ mutation in a Han Chinese population [35], while the 1095T $>\mathrm{C}$ mutation is a risk factor for hearing impairment [36]. Thus, we proposed that the combination of these secondary and primary mtDNA mutations may be involved in the pathogenesis of DCM.

In addition, the complete mitochondrial genomes of 9 subjects carrying 1 of putative pathogenic mt-tRNA mutations have been assigned to East Asian mitochondrial haplogroups based on the PhyloTree database (http:// www.phylotree.org/) [20]. According to their distinct sets of polymorphisms, the mtDNA of these 9 subjects belonged to East Asian mitochondrial haplogroups F2, D4, G2a, D4, M22b, Z3, G1a1, B5, and B5b2, respectively [37].

\section{Analysis of mtDNA Content}

As shown in Figure 3a, we found that patients carrying these putative pathogenic mt-tRNA mutations had a lower level of mtDNA copy numbers when compared to the controls $(p=0.013)$.

\section{Decrease in ATP Production}

A defect in ATP production is an important cause for mitochondrial dysfunction. For this purpose, the ATP level was examined by luciferin/luciferase assay, as shown in Figure 3b. We noticed that DCM patients with these
mt-tRNA mutations had a much lower level of ATP when compared to the healthy subjects $(p=0.0134)$.

\section{ROS Increased Significantly}

Since mitochondria generate ATP via OXPHOS and release ROS as a toxic byproduct, overproduction of ROS may cause mitochondrial dysfunction [38]. For this purpose, the ROS levels in DCM patients with putative pathogenic mt-tRNA mutations and controls were analyzed, as displayed in Figure 3c. The ROS levels in the DCM group were significantly higher than in control subjects $(p=$ 0.0127).

\section{Discussion}

In the present study, we analyzed the frequencies of mt-tRNA mutations in a cohort of 318 patients with DCM and 200 age- and gender-matched controls. To the best of our knowledge, this is the first report regarding the association of mt-tRNA mutations with DCM. In fact, mitochondria are most abundant in cells with high energy demands, notably striated muscles. Moreover, the heart is the most metabolically active organ in the body and possesses the highest content of mitochondria of any tissue [39], comprising about $25 \%$ of cell volume in the human myocardium [40]. Mutations in mtDNA have the potential to affect OXPHOS and in turn cellular death, but the mechanisms whereby these mutations cause DCM are largely unknown [41].

Through PCR and direct sequencing analysis, we identified 7 potentially pathogenic mutations: MT-TL1 3302A $>$ G, MT-TI 4295A $>$ G, MT-TM 4435A $>$ G, MT-TA 5655T $>$ C, MT-TH 12201T $>$ C, MT-TE 14692A $>$ G, and MT-TT $15927 \mathrm{G}>\mathrm{A}$. Of these, the $3302 \mathrm{~A}>\mathrm{G}$ mutation was located 2 nucleotides away from the $5^{\prime}$ terminal MT-TL1, 
which was highly conserved from different species. Recent experimental studies indicated that the 3302A $>\mathrm{G}$ mutation caused the severe respiratory chain complex I deficiency and lowered complex IV activity [42]. Moreover, a significant reduction in the steady-state level of MT-TL1 was observed in cells carrying this mutation [43]. Clinically, the 3302A $>\mathrm{G}$ mutation was found to be associated with polycystic ovary syndrome [44] and mitochondrial encephalomyopathy, lactic acidosis, and stroke-like symptoms (MELAS) [45]. In addition, the $4295 \mathrm{~A}>\mathrm{G}$ and $4435 \mathrm{~A}>\mathrm{G}$ mutations affected a highly conserved adenosine at position 37 in the anticodon stem of MT-TI and MT-TM, respectively. Notably, both of them introduced a tRNA methyltransferase 5 (TRMT5)-catalyzed $\mathrm{m}^{1} \mathrm{G} 37$ modification of the corresponding tRNAs [46]. Functional analysis of cybrid cells containing these mutations showed significant impairment in the steadystate level, as well as the aminoacylation ability of tRNAs; the failure in tRNA metabolism led to the impairment of mitochondrial translation, ATP, and increasing the ROS production $[47,48]$. Therefore, the $4295 \mathrm{~A}>\mathrm{G}$ and $4435 \mathrm{~A}>\mathrm{G}$ mutations may cause mitochondrial dysfunction that was responsible for DCM, while the 5655T $>C$ mutation disrupted a very conserved base-pairing (1A$72 \mathrm{U}$ ) at the acceptor stem of ME-TA. An in vitro processing analysis showed that the $5655 \mathrm{~T}>\mathrm{C}$ mutation reduced the efficiency of ME-TA precursor $5^{\prime}$ end cleavage catalyzed by RNase $\mathrm{P}[49]$. Moreover, $\sim 41 \%$ reduction in the steady-state level of ME-TA was observed in cell lines carrying the $5655 \mathrm{~T}>\mathrm{C}$ mutation $[50,51]$. Similarly, the heteroplasmic $12201 \mathrm{~T}>\mathrm{C}$ mutation destabilized a conservative base-pairing (5A-68U) on the acceptor stem of MTTH. tRNA northern analysis revealed that the $12201 \mathrm{~T}>\mathrm{C}$ mutation causes $\sim 75 \%$ reduction in the steady-state level of MT-TH. An in vivo protein labeling analysis showed an $\sim 47 \%$ reduction in the rate of mitochondrial translation in cells carrying the $12201 \mathrm{~T}>\mathrm{C}$ mutation $[52,53]$. Furthermore, the $14692 \mathrm{~A}>\mathrm{G}$ mutation caused loss of $\Psi 55$ modification and increased angiogenin-mediated endonucleolytic cleavage in mutant MT-TE. An approximately $65 \%$ decrease in the steady-state level of MT-TE was found in mutant cells as compared to control cells [54]. A failure in MT-TE metabolism impaired mitochondrial translation, especially for polypeptides with a high proportion of glutamic acid codons, such as ND1, ND6, and $\mathrm{CO} 2$, in mutant cells, whereas the $15927 \mathrm{G}>\mathrm{A}$ mutation affected a highly conserved guanine at position 42 at the anticodon stem of MT-TT, destabilizing the conservative base-pairing (28C-42G) [55]. Northern blot analysis revealed a $60 \%$ decrease in the steady-state level of MT-TT in the mutant cell lines. Western blot analysis showed the variable reductions of $4 \mathrm{mtDNA}$ encoding proteins, especially for marked decrease of MT-ND1 and MT-CYTB observed in mutant cell lines [56].

To see whether these mt-tRNA mutations caused the mitochondrial dysfunction that was responsible for DCM, we analyzed the mtDNA copy number, ATP, and ROS in patients carrying these pathogenic mtDNA mutations. Consequently, we found that patients carrying these mutations had a lower level of mtDNA copy number when compared to the controls. In fact, levels of $\mathrm{mtD}$ NA copy number were directly correlated with energy reserves, oxidative stress, and changes in mitochondrial membrane potential [57]. According to the most accepted theory, reductions in mtDNA copy number were associated with downregulation of mitochondrial transcription and decreased levels of proteins involved in OXPHOS [58]. Thus, it can be speculated that the reduction in respiratory capacity induced by reduced mtDNA copy number levels may have important pathogenic consequences. Moreover, compared to the controls, there was an approximately $35 \%$ decrease in ATP production in the mutant cell lines, whereas $\sim 42 \%$ enhancement of ROS production was observed in this study. In fact, the impairment of OXPHOS will increase the production of ROS in mutant cells carrying these pathogenic mt-tRNA mutations. The overproduction of ROS can establish a vicious cycle of oxidative stress in mitochondria [59]. As a result, these biochemical defects can cause dysfunction or apoptosis in cardiac muscle cells, thereby producing the clinical phenotype.

Based on these observations, we propose that the possible molecular mechanisms underlying mt-tRNA mutations in the clinical expression of DCM may be as follows: first, the mutation itself disrupts the secondary structure of mt-tRNA, thus causing a failure in mt-tRNA metabolism, such as CCA addition, post-transcriptional modification, or aminoacylation [60]. Failures in mt-tRNA metabolism caused by these mutations would impair mitochondrial protein synthesis and respiration [61]. Second, abnormal mitochondrial respiration causes oxidative stress and uncoupling of oxidative pathways for ATP synthesis, which causes apoptosis or necrosis in the endothelial cells and contributes to DCM.

In summary, our study provided evidence that mitochondrial genetic defects may lead to DCM. In particular, MT-TL1 3302A $>$ G, MT-TI 4295A $>$ G, MT-TM 4435A $>$ G, MT-TA5655T $>$ C,MT-TH12201T $>$ C,MT-TE14692A $>$ G, and MT-TT 15927G >A mutations altered the structure and function of their tRNAs, thereby causing mitochon- 
drial dysfunctions and long-standing increase of ROS in cardiovascular cells. These 7 mutations may be the inherited risk factors for DCM. Thus, our findings may provide new insights into the understanding of the pathophysiology and valuable information for the management and treatment of DCM.

\section{Acknowledgement}

We thank the members of our department for discussion.

\section{Statement of Ethics}

The study protocol was reviewed and approved by the ethics committee of Tianjin Chest Hospital (approval number: 2020YS030-01), and the study was conducted in accordance with the Declaration of Helsinki and the International Conference on Harmonization Guidelines for Good Clinical Practice. Written informed consent was obtained from all subjects enrolled in this study.

\section{Conflict of Interest Statement}

The authors declare that they have no conflicts of interest.

\section{Funding Sources}

This work was supported by a grant from Tianjin Municipal Health and Health Committee (No. zc20147).

\section{Author Contributions}

P.L. designed the study, Y.Q. and Z.W. performed the genetic screening of mt-tRNA genes, Y.B. and Y.J. enrolled the blood samples of DCM and healthy controls, Y.Q. and P.L. wrote the paper. All authors have approved the manuscript.

\section{Data Availability Statement}

All data generated or analyzed during this study are included in this article. Further enquiries can be directed to the corresponding author.

\section{References}

1 Schultheiss HP, Fairweather D, Caforio AL Escher F, Hershberger RE, Lipshultz SE, et al. Dilated cardiomyopathy. Nat Rev Dis Primers. 2019 May;5(1):32.

2 Lyu Y, Chen J, Xu H. The pathogenic gene screening in a Chinese familial dilated cardiomyopathy pedigree from Hubei. Gene. 2018 Feb;642:159-62.

3 Fan LL, Huang H, Jin JY, Li JJ, Chen YQ, Zhao $\mathrm{SP}$, et al. Whole exome sequencing identifies a novel mutation $(\mathrm{c} .333+2 \mathrm{~T}>\mathrm{C})$ of TNNI3K in a Chinese family with dilated cardiomyopathy and cardiac conduction disease. Gene. 2018 Mar;648:63-7.

4 Reichart D, Magnussen C, Zeller T, Blankenberg S. Dilated cardiomyopathy: from epidemiologic to genetic phenotypes. J Intern Med. 2019 Oct:286(4):362-72.

5 Wüst RCI, Coolen BF, Held NM, Daal MRR, Alizadeh Tazehkandi V, Baks-Te Bulte L, et al. The antibiotic doxycycline impairs cardiac mitochondrial and contractile function. Int J Mol Sci. 2021 Apr;22(8):4100.

6 Spiroski AM, Niu Y, Nicholas LM, AustinWilliams S, Camm EJ, Sutherland MR, et al. Mitochondria antioxidant protection against cardiovascular dysfunction programmed by early-onset gestational hypoxia. FASEB J. 2021 May;35(5):e21446.

7 Tian R, Colucci WS, Arany Z, Bachschmid MM, Ballinger SW, Boudina S, et al. Unlocking the secrets of mitochondria in the cardiovascular system: path to a cure in heart failure: a report from the 2018 National Heart, Lung, and Blood Institute workshop. Circulation. 2019 Oct;140(14):1205-16.

8 Cao YP, Zheng M. Mitochondrial dynamics and inter-mitochondrial communication in the heart. Arch Biochem Biophys. 2019 Mar; 663:214-9.

9 Castri L, Melendez-Obando M, Villegas-Palma R, Barrantes R, Raventos H, Pereira R, et al. Mitochondrial polymorphisms are associated both with increased and decreased longevity. Hum Hered. 2009;67(3):147-53.

10 Farjadian S, Sazzini M, Tofanelli S, Castrì L, Taglioli L, Pettener D, et al. Discordant patterns of mtDNA and ethno-linguistic variation in 14 Iranian ethnic groups. Hum Hered. 2011;72(2):73-84.

11 Goldstein JD, Shanske S, Bruno C, Perszyk AA. Maternally inherited mitochondrial cardiomyopathy associated with a C-to-T transition at nucleotide 3303 of mitochondrial DNA in the tRNA Leu(UUR) gene. Pediatr Dev Pathol. 1999 Jan-Feb;2(1):78-85.

12 Vilarinho L, Santorelli FM, Rosas MJ, Tavares C, Melo-Pires M, DiMauro S. The mitochondrial A3243G mutation presenting as severe cardiomyopathy. J Med Genet. 1997 Jul;34(7): 607-9.

13 Hagen CM, Aidt FH, Havndrup O, Hedley PL, Jespersgaard C, Jensen M, et al. MT-CYB mutations in hypertrophic cardiomyopathy. Mol Genet Genomic Med. 2013 May; 1(1):5465.

14 Liu Z, Song Y, Gu S, He X, Zhu X, Shen Y, et al. Mitochondrial ND5 $12338 \mathrm{~T}>\mathrm{C}$ variant is associated with maternally inherited hypertrophic cardiomyopathy in a Chinese pedigree. Gene. 2012 Sep;506(2):339-43.

15 Elliott P, Andersson B, Arbustini E, Bilinska $\mathrm{Z}$, Cecchi F, Charron P, et al. Classification of the cardiomyopathies: a position statement from the European society of cardiology working group on myocardial and pericardial diseases. Eur Heart J. 2008 Jan;29(2): 270-6.

16 Merlo M, Pivetta A, Pinamonti B, Stolfo D, Zecchin M, Barbati G, et al. Long-term prognostic impact of therapeutic strategies in patients with idiopathic dilated cardiomyopathy: changing mortality over the last 30 years. Eur J Heart Fail. 2014 Mar;16(3):317-24.

17 Shuai J, Shi J, Liang Y, Ji F, Gu L, Yuan Z. Mutational analysis of mitochondrial tRNA genes in 138 patients with Leber's hereditary optic neuropathy. Ir J Med Sci. 2021 May. Online ahead of print.

18 Andrews RM, Kubacka I, Chinnery PF, Lightowlers RN, Turnbull DM, Howell N. Reanalysis and revision of the Cambridge reference sequence for human mitochondrial DNA. Nat Genet. 1999 Oct;23:147.

19 Xue L, Wang M, Li H, Wang H, Jiang F, Hou $\mathrm{L}$, et al. Mitochondrial tRNA mutations in 2070 Chinese Han subjects with hypertension. Mitochondrion. 2016 Sep;30:208-21.

20 van Oven M, Kayser M. Updated comprehensive phylogenetic tree of global human mitochondrial DNA variation. Hum Mutat. 2009 Feb;30(2):E386-94. 
21 Thyagarajan B, Wang R, Nelson H, Barcelo H, Koh WP, Yuan JM. Mitochondrial DNA copy number is associated with breast cancer risk. PLoS One. 2013 Jun;8(6):e65968.

22 Jiang Z, Teng L, Zhang S, Ding Y. Mitochondrial ND1 T4216C and ND2 C5178A mutations are associated with maternally transmitted diabetes mellitus. Mitochondrial DNA A DNA Mapp Seq Anal. 2021 Mar;32(2):59-65.

23 Ding Y, Xia BH, Zhang CJ, Zhuo GC. Mitochondrial tRNALeu(UUR) C3275T, tRNAGln T4363C and tRNALys A8343G mutations may be associated with PCOS and metabolic syndrome. Gene. 2018 Feb;642:299-306.

24 Victor VM, Rovira-Llopis S, Bañuls C, DiazMorales N, Martinez de Marañon A, RiosNavarro C, et al. Insulin resistance in PCOS patients enhances oxidative stress and leukocyte adhesion: role of myeloperoxidase. PLoS One. 2016 Mar;11(3):e0151960.

25 Ruiz-Pesini E, Wallace DC. Evidence for adaptive selection acting on the tRNA and rRNA genes of human mitochondrial DNA. Hum Mutat. 2006 Nov;27(11):1072-81.

26 Finsterer J, Bittner R, Bodingbauer M, Eichberger H, Stöllberger C, Blazek G. Complex mitochondriopathy associated with $4 \mathrm{mtD}$ NA transitions. Eur Neurol. 2000;44(1):3741.

27 Tang S, Batra A, Zhang Y, Ebenroth ES, Huang T. Left ventricular noncompaction is associated with mutations in the mitochondrial genome. Mitochondrion. 2010 Jun;10: 350-7.

28 Yano T, Nishio SY, Usami S; Deafness Gene Study Consortium. Frequency of mitochondrial mutations in non-syndromic hearing loss as well as possibly responsible variants found by whole mitochondrial genome screening. J Hum Genet. 2014 Feb;59(2):1006.

29 Im I, Jang MJ, Park SJ, Lee SH, Choi JH, Yoo $\mathrm{HW}$, et al. Mitochondrial respiratory defect causes dysfunctional lactate turnover via AMP-activated protein kinase activation in human-induced pluripotent stem cell-derived hepatocytes. J Biol Chem. 2015 Dec; 290(49):29493-505.

30 Guan M, Enriquez J, Fischel-Ghodsian N, Puranam R, Lin C, Marion M, et al. The deafness-associated mtDNA 7445 mutation, which affects tRNASer (UCN) precursor processing, has long-range effects on NADH dehydrogenase ND6 subunit gene expression. Mol Cell Biol. 1998 Oct;18(10):5868-79.

31 Zhu Y, Qian Y, Tang X, Wang J, Yang L, Liao $Z$, et al. Aminoglycoside-induced and nonsyndromic hearing loss is associated with the G7444A mutation in the mitochondrial COI/ tRNASer(UCN) genes in two Chinese families. Biochem Biophys Res Commun. 2006 Apr;342(3):843-50.
32 Qian Y, Zhou X, Hu Y, Tong Y, Li R, Lu F, et al. Clinical evaluation and mitochondrial DNA sequence analysis in three Chinese families with Leber's hereditary optic neuropathy. Biochem Biophys Res Commun. 2005 Jul; 332(2):614-21.

33 Zhang J, Zhou X, Zhou J, Li C, Zhao F, Wang Y, et al. Mitochondrial ND6 T14502C variant may modulate the phenotypic expression of LHON-associated G11778A mutation in four Chinese families. Biochem Biophys Res Commun. 2010 Sep;399(4):647-53.

34 Kokaze A, Ishikawa M, Matsunaga N, Karita $\mathrm{K}$, Yoshida M, Ohtsu T, et al. Longevity-associated mitochondrial DNA 5178 C/A polymorphism modulates the effects of coffee consumption on erythrocytic parameters in Japanese men: an exploratory cross-sectional analysis. J Physiol Anthropol. 2014 Dec;33(1): 37.

35 Ji Y, Zhang AM, Jia X, Zhang YP, Xiao X, Li $S$, et al. Mitochondrial DNA haplogroups M7b1'2 and M8a affect clinical expression of Leber hereditary optic neuropathy in Chinese families with the m.11778G-->a mutation. Am J Hum Genet. 2008 Dec;83(6):760-8.

36 Li Z, Li R, Chen J, Liao Z, Zhu Y, Qian Y, et al. Mutational analysis of the mitochondrial $12 \mathrm{~S}$ rRNA gene in Chinese pediatric subjects with aminoglycoside-induced and non-syndromic hearing loss. Hum Genet. 2005 Jun;117(1): 9-15.

37 Kong QP, Bandelt HJ, Sun C, Yao YG, Salas A, Achilli A, et al. Updating the East Asian mtDNA phylogeny: a prerequisite for the identification of pathogenic mutations. Hum Mol Genet. 2006 Jul;15(13):2076-86.

38 Fu X, Tang J, Wen P, Huang Z, Najafi M. Redox interactions-induced cardiac toxicity in cancer therapy. Arch Biochem Biophys. 2021 Sep;708:108952.

39 Brown DA, Perry JB, Allen ME, Sabbah HN, Stauffer BL, Shaikh SR, et al. Expert consensus document: mitochondrial function as a therapeutic target in heart failure. Nat Rev Cardiol. 2017 Apr;14(4):238-50.

40 Johannsen DL, Ravussin E. The role of mitochondria in health and disease. Curr Opin Pharmacol. 2009 Dec;9(6):780-6.

41 Kamps R, Szklarczyk R, Theunissen TE, Hellebrekers DMEI, Sallevelt SCEH, Boesten IB, et al. Genetic defects in mtDNA-encoded protein translation cause pediatric, mitochondrial cardiomyopathy with early-onset brain disease. Eur J Hum Genet. 2018 Apr;26(4):53751.

42 Maniura-Weber K, Helm M, Engemann K, Eckertz S, Möllers M, Schauen M, et al. Molecular dysfunction associated with the human mitochondrial $3302 \mathrm{~A}>\mathrm{G}$ mutation in the MTTL1 (mt-tRNALeu(UUR)) gene. Nucleic Acids Res. 2006;34(22):6404-15.
43 Bindoff LA, Howell N, Poulton J, McCullough DA, Morten KJ, Lightowlers RN, et al. Abnormal RNA processing associated with a novel tRNA mutation in mitochondrial DNA: a potential disease mechanism. J Biol Chem. 1993 Sep;268(26):19559-64.

44 Ding Y, Zhuo G, Zhang C. The mitochondrial tRNALeu(UUR) A3302G mutation may be associated with insulin resistance in woman with polycystic ovary syndrome. Reprod Sci. 2016 Feb;23(2):228-33.

45 Goto M, Komaki H, Saito T, Saito Y, Nakagawa E, Sugai K, et al. MELAS phenotype associated with m.3302A $>$ G mutation in mitochondrial tRNA(Leu(UUR)) gene. Brain Dev. 2014 Feb;36(2):180-2.

46 Lin H, Miyauchi K, Harada T, Okita R, Takeshita E, Komaki H, et al. CO2-sensitive tRNA modification associated with human mitochondrial disease. Nat Commun. 2018 May;9(1):1875.

47 Meng F, Zhou M, Xiao Y, Mao X, Zheng J, Lin $\mathrm{J}$, et al. A deafness-associated tRNA mutation caused pleiotropic effects on the $1 \mathrm{G} 37$ modification, processing, stability and aminoacylation of tRNAIle and mitochondrial translation. Nucleic Acids Res. 2021 Jan;49(2): 1075-93.

48 Zhou M, Xue L, Chen Y, Li H, He Q, Wang B, et al. A hypertension-associated mitochondrial DNA mutation introduces an m1G37 modification into tRNAMet, altering its structure and function. J Biol Chem. 2018 Jan; 293(4):1425-38.

49 Holzmann J, Frank P, Löffler E, Bennett KL, Gerner C, Rossmanith W. RNase P without RNA: identification and functional reconstitution of the human mitochondrial tRNA processing enzyme. Cell. 2008 Oct;135(3): 462-74.

50 Jiang P, Wang M, Xue L, Xiao Y, Yu J, Wang $\mathrm{H}$, et al. A hypertension-associated tRNAAla mutation alters tRNA metabolism and mitochondrial function. Mol Cell Biol. 2016 Jun; 36(14):1920-1930.

51 Li X, Fischel-Ghodsian N, Schwartz F, Yan Q, Friedman RA, Guan MX. Biochemical characterization of the mitochondrial tRNASer(UCN) T7511C mutation associated with nonsyndromic deafness. Nucleic Acids Res. 2004 Feb;32(3):867-77.

52 Yan X, Wang X, Wang Z, Sun S, Chen G, He $\mathrm{Y}$, et al. Maternally transmitted late-onset non-syndromic deafness is associated with the novel heteroplasmic T12201C mutation in the mitochondrial tRNAHis gene. J Med Genet. 2011 Oct;48(10):682-90.

53 Gong $\mathrm{S}$, Peng $\mathrm{Y}$, Jiang $\mathrm{P}$, Wang $\mathrm{M}$, Fan $\mathrm{M}$, Wang $\mathrm{X}$, et al. A deafness-associated tRNAHis mutation alters the mitochondrial function, ROS production and membrane potential. Nucleic Acids Res. 2014 Jul;42(12):8039_ 48. 
54 Wang M, Liu H, Zheng J, Chen B, Zhou M, Fan W, et al. A Deafness- and diabetes-associated tRNA mutation causes deficient pseudouridinylation at position 55 in tRNAGlu and mitochondrial dysfunction. J Biol Chem. 2016 Sep;291(40):21029-41.

55 Ding Y, Teng YS, Zhuo GC, Xia BH, Leng JH. The mitochondrial tRNAHis G12192A mutation may modulate the clinical expression of deafness-associated tRNAThr G15927A mutation in a Chinese pedigree. Curr Mol Med. 2019;19(2):136-46.
56 Zhang J, Ji Y, Liu X, Chen J, Wang B, Zhang $\mathrm{M}$, et al. Leber's hereditary optic neuropathy caused by a mutation in mitochondrial tRNAThr in eight Chinese pedigrees. Mitochondrion. 2018 Sep;42:84-91.

57 Guha M, Avadhani NG. Mitochondrial retrograde signaling at the crossroads of tumor bioenergetics, genetics and epigenetics. Mitochondrion. 2013 Nov; 13(6):577-91.

58 Jeng JY, Yeh TS, Lee JW, Lin SH, Fong TH, Hsieh RH. Maintenance of mitochondrial DNA copy number and expression are essential for preservation of mitochondrial function and cell growth. J Cell Biochem. 2008 Feb;103(2):347-57.
59 Böttger EC, Schacht J. The mitochondrion: a perpetrator of acquired hearing loss. Hear Res. 2013 Sep;303:12-9.

60 Brulé H, Holmes WM, Keith G, Giegé R, Florentz $\mathrm{C}$. Effect of a mutation in the anticodon of human mitochondrial tRNAPro on its post-transcriptional modification pattern. Nucleic Acids Res. 1998 Jan;26(2):537-43.

61 Wallace DC. A mitochondrial paradigm of metabolic and degenerative diseases, aging, and cancer: a dawn for evolutionary medicine. Annu Rev Genet. 2005;39:359-407. 